\title{
The Connotations of Pet Expressions in Jordanian Spoken Arabic
}

\author{
Helen A. Al-Ghoweri \\ The World Islamic Science \& Education University (WISE), Amman, Jordan \\ Ayman Yasin \\ Princess Sumayya University for Technology, Jordan \\ Jibrel Al-Saudi \\ The World Islamic Science \& Education University (WISE), Amman, Jordan
}

\begin{abstract}
The primary objective of this study is to examine the connotation of pet expressions when used to describe people in Jordanian Spoken Arabic (JSA), that is, the wide array of negative and positive associations that pet expressions bring with them. When defining animals,al-mu'jamal-wasi:tt and al-mu'jamaljami' define most of the animal expressions along with their connotations. The present study investigates the connotations of pets in Jordanian Spoken Arabic. To this end, the researchers distributed an open ended questionnaire to the subjects that could provide rich qualitative data. This, in turn, will give the researchers an opportunity to gain insight in the subjects' opinions on the connotation of pets in JSA. The questionnaire consisted of (11) Jordanian spoken Arabic sentences. Each sentence included a pet expression which is used in JSA. After collecting the questionnaire the researchers tested the connotations of pet expressions in JSA

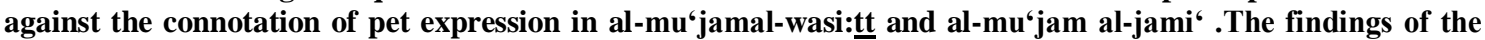
study suggest that in some cases the connotation changed from positive in the two lexicons to negative in JSA or vice versa. In others, the connotation remained the same but changed from a connotation to another.
\end{abstract}

Index Terms - pet expressions, Jordanian spoken Arabic (JSA), connotation

\section{INTRODUCTION}

This paper investigates the connotations of pets in Jordanian spoken Arabic (JSA). The positive as well as the negative connotations of pets reflect features, characteristics, and behaviors which are employed to convey certain meanings. Connotative meaning is concerned with the communicative value of lexemes and expressions rather than with the conceptual one (Leech, 1974). Connotations are relatively unstable; they differ considerably according to culture and the experience of the individual. Leech believes that all speakers of a particular language share the same denotative meaning just as they share the same syntax, phonology and morphology (P. 14).

Connotative meaning is not definitive as it includes the subjective and objective senses of the utterance. The denotative meaning of a word can be thought of in terms of a limited set of semantic representation as its rules are finite Connotative meaning is may be different according to culture, languages and its speakers and their experiences. Nonpropositional meaning can have expressive, presupposed, or evoked senses (Cruse, 1986). In this study, connotation, used in opposition with denotation and sense, refers to the expressive meaning which makes it useful for speakers to communicate their evaluations or attitudes. Dictionaries seek to define meaning. However, one of the problems of dictionaries is that they impose, by abstraction of one or more a rigidity of meaning that words do not often show in reality, once words are put into a context, their denotative meanings become more flexible. Moreover, not all dictionaries and lexicons include the connotations which words may carry (Kovecses, 2010).

Connotative meaning is the meaning given to the word over and above the denotative meaning which it has in that context by the fact that it brings to mind another meaning of the same word, and it differs from its sense, denotation and reference (Allan, 2007). Animal words are associated with cultural connotation. Therefore, their connotations vary across cultures and languages. For example, The word hima:r refers to the animal 'donkey', but to call someone hima:r in Jordanian Arabic means connotatively 'stupid'.

Animals have always been part of people's development. At least they have been considered as food for humans. Accordingly, animals play a significant role in the people's life. Newmark (1988) points out that animal expressions can be utilized to describe undesirable human attributes. Research on animal expressions has revealed the use of different categories related to animals. Animal names have been found in various metaphorical expressions that refer to people.

Peled-Shapira (2009) studied the metaphors which were derived from the animal world in the works of the exiled Iraqi Communist writer GhaibTu Ma Farmasi. The animal metaphors were used to depict the writer as leftist intellectual. They, further, involve transference of meanings depending on culture and context. The study found that animal metaphors contribute to aesthetics and poetic elegance of literary works. 
Rodriguez (2009) studied animal metaphors for women in two languages: English and Spanish. "The study explored perceptions of womanhood through animal metaphors and figurative uses of animal names applied to females in both English and Spanish". Animal metaphors were proven to reinforce the stereotypical image of women. Moreover, the study found that the names of certain pet animals have positive connotations, while wild animals express undesirable associations. Pet animals reflect the idea that women entertain men and provide food to men and beget children.

Anjomshoa and Sadighi (2015) conducted a study within semantic - pragmatic framework. The researchers attempt to show some lingual misunderstandings in the usage of animal expressions animal expressions. The research studied the connotations between the English and Persian animal words. The study found that animal words have cultural connotations in each language. Most cultural connotations in Persian are different from the English ones. The researchers found out that differences in animal connotations between English and Persian are caused by religion, history, geographical environment and customs.

Al-Rawashdeh (2016) conducted a study on the connotations of animal names used in describing people in the city of Shoback-Jordan. The study also aimed at investigating whether the animal names are metaphorically to describe males and females. The researcher employs the semi-structured interview as a research method. 20 Shobackian people were interviewed. The researcher reported that people in the city of Shoback use animal names positively and negatively, but negative uses. However, the animal names used to describe both sexes outnumber the names of animals used to describe males only or females only.

Salman and Barjes (2019) examined dog proverbs with the aim of showing the way in which the English and the Iraqi Arabs interpret and use animal proverbs. The researchers analyzed the selected dog proverbs adopting Leech's (1981) connotations and Holmes' (2013) social factors. The research concluded that English and Iraqi Arabs have different attitudes towards their animal proverbs which give the proverbs different connotations, and in turn, influence the way they interact with social factors, this conclusion goes hand in hand with Abdullah (2011) who investigated Malay proverbs related to the dog. According to the researchers, both cultures associate the frequent use of dog proverbs with the lower prestigious occupations (e.g., farmers). Moreover, the English are more flexible in using animal proverbs with socially remote participants more than the Iraqi Arabs do. Finally, the only variable in the two cultures is the informality variables.

The present study tries to explore the connotation of pet expressions in Jordanian spoken Arabic. Animal expressions and particularly pet expressions are used to describe people, express words' meanings and have cultural associations (Lakoff and Turner, 1989). That is to say, they can be used either literally or connotatively to convey their associative meanings. The language user can appeal to his or her linguistic knowledge to support a belief. The present study seeks to answer the following questions:

1. What are the positive and negative connotations of pet expressions in JSA?

2. Do the connotation of pets in al-mu 'jamal-wasi:t and al-mu 'jamal-jami ' agree on positive and negative connotations and associations of pets in JSA?

\section{Methodology}

\section{A. Subjects}

The sample of the study consisted of (20) BA native speakers of JSA enrolled in the English Language and literature Program at the World Islamic Science and Education University (WISE). There were 12 female students and 8 male students. The age range of the subjects was between 20 and 22. Both groups reported that they have studied English language for more than ten years. The subjects have taken at least fifteen courses in English Language and literature including a course in linguistics where they studied the terms 'connotation' vs. 'denotation'.

\section{B. Data Collection}

The researchers distributed an open ended questionnaire to the subjects that could provide rich qualitative data. This, in turn, will give the researchers an opportunity to gain insight of the subjects' opinions on the connotation of pets in JSA. The researcher will analyze the data in light of the results obtained.

The questionnaire consisted of (11) Jordanian spoken Arabic sentences. Each sentence includes a pet expression which is used in JSA. The research used the following Pet expressions: hima: $r$ 'a donkey', 'asfu:ra- $h$ 'a bird', arnab 'a rabbit', hamameih 'a dove', kharuf 'a sheep', battah 'a duck' kalb 'a dog' hisa:n 'a horse' bisah 'a cat' ,babaghah 'a parrot' and $m$ 'azeh 'a goat'. The pet expressions used in the study have been collected by the researchers based on her own experience as native speakers of JSA. The researchers asked the subject to mention the connotation of the pet expressions used in the study and to indicate whether the pet expression in each sentence has a negative or a positive connotation. The subjects were given fifteen minutes to complete the questionnaire. After collecting the questionnaire the researchers tested the connotations of pet expressions in JSA against the connotations of pet expression in almu'jamal-wasi:tt and al-mu'jamal-jami'. These two lexicons arrange words in an alphabetical order with crossreferences to their roots. The researchers chose these two lexicons list the meanings of words along with their connotations.

\section{FINDINGS AND DisCUSSION}


The following table illustrates the findings of the present study:

\begin{tabular}{|l|l|l|l|l|}
\hline \multicolumn{1}{|c|}{ Pet Expression } & \multicolumn{2}{c|}{$a l-m u$ 'jamal-wasi:tt and al-mu 'jam al-jami } & \multicolumn{2}{c|}{ J A } \\
\hline & Positive connotations & Negative connotations & Positive connotations & Negative connotations \\
\hline hima:r'a donkey' & & $\checkmark$ & $\checkmark$ & $\checkmark$ \\
\hline asfu:ra- $h$ 'a bird' & $\checkmark$ & & $\checkmark$ & \\
\hline arnab 'a rabbit' & $\checkmark$ & $\checkmark$ & $\checkmark$ & $\checkmark$ \\
\hline hamameih 'a dove' & $\checkmark$ & & $\checkmark$ & \\
\hline kharuf'a sheep' & ----- & $-\cdots---$ & & \\
\hline battah 'a duck' & $\checkmark$ & & $\checkmark$ & $\checkmark$ \\
\hline kalb 'a dog' & $\checkmark$ & & & $\checkmark$ \\
\hline hisa: $n$ 'a horse' & $\checkmark$ & & $\checkmark$ & \\
\hline bisah 'a cat' & ---- & ----- & $\checkmark$ & $\checkmark$ \\
\hline babaghah 'a parrot' & $\checkmark$ & $\checkmark$ & $\checkmark$ & $\checkmark$ \\
\hline m 'azeh 'a goat' & ----- & ----- & & $\checkmark$ \\
\hline
\end{tabular}

Let's start with the first pet. The word hima:r 'a donkey' is defined in al-mu 'jamal-jami ' as "an animal related to horses ,but it is smaller than the horse since it has short hair in mane ,a tail and very large ears". It is used to carry things and move from one place to another. According to the same lexicon, the word hima: $r$ 'a donkey' connotes loud voices. al-mu'jamal-wasi:tt states the same definition, but according to al-mu'jamal-wasi:tt the pet expression hima:r 'a donkey' connotes bad men with bad reputations.

$\begin{array}{llll}\text { 1. hima:r u } & \text { qajid } & \text { hima:r (JSA) } \\ \text { donkey and leading } & \text { a donkey }\end{array}$

'A donkey leading a donkey'

The study shows that $85 \%$ of the subjects indicated that the word hima:r 'a donkey' is used in the above context to connote stupidity while $10 \%$ indicated that hima:r 'a donkey' connotes difficulty in changing opinions. 5\% of the subjects, however, indicated that hima: $r$ 'a donkey' connotes strength. The 95\%subjects also indicated that hima:r 'a donkey' has a negative connotation, and 5\% of the subjects indicated that it has a positive connotation. The connotations of hima:r 'a donkey' are negative in these two lexicons. Nonetheless, it seems that the connotations of hima:r'a donkey' in JSA do not go along with the connotations mentioned in al-mu 'jamal-jami .

The second word 'asfu;ra-h 'a sparrow'. 'Asfu:ra-h in al-mu'jamal-wasi:tt and al-mu 'jamal-jami' connotes light things and melodious sounds.

2. btokil zai il-asfu:ra-h (JSA)
eat:3sF like the-bird-F

'(She) eats like a (female) bird'

The study reveals that $20 \%$ of the subjects indicated that 'asfu;ra- $h$ 'a bird' is used in the above context to describe a person who eats in a prestigious way. The other $80 \%$ of the subjects indicated that 'asfu;ra-h 'a bird' is used in 'btokil zai ilasfu:ra- $h$ to connote a person who does not eat much or a person who eats light meals. This connotation goes hand in hand with the connotations in al-mu'jamal-wasi:tt and al-mu'jamal-jami' since both lexicons mention that 'asfu;ra- $h$ 'a bird' connotes light things. It is worth mentioning that 'asfu;ra- $h$ 'a bird' in JSA may connote a person who has a melodious voice. The subjects of the study identified that 'asfu;ra-h 'a bird' has positive connotations in JSA. It seems that the connotations of 'asfu;ra-hin al-mu'jamal-wasi: tt and al-mu' jamal-jami' are also positive.

Third, the word arnab 'a rabbit' in al-mu 'jamal-jami' is a member of a family of long-eared short-tailed mammal with long hind legs. It connotes being humiliated, and it also connotes running from the predator.

3. arnab sa'i:d fi bait-uh (JSA)

rabbit happy in home -his

'Happy rabbit in his home'

The present study shows that $60 \%$ of the subjects manifested that arnab 'a rabbit' is used to describe a person who is under his wife's control, and $40 \%$ of the subjects indicated that arnab 'a rabbit' connotes a person who is fast in doing the housework. $60 \%$ of the subject stated that arnab 'a rabbit' has negative connotations. While $40 \%$ of the subjects indicated that arnab 'a rabbit' has a negative connotation. The connotations in JSA agree with the connotations mentioned in al-mu jamal-wasi:tt and al-mu jamal-jami' which can also be classified as positive when connotes a fast runner and negative when connotes being humiliated.

Moving to the word hamameih 'a dove', al-mu 'jamal-wasi:tt and al-mu 'jamal-jami' lists this word as referring to any of numerous pigeons; especially a small wild pigeon, and it connotes a person who sends messages to others. In the past, people used to send messages to each other by doves which had the ability to get back to their place easily. In accordance with this line of thought, hamameih 'a dove' carries a positive connotation in these two lexicons.

4. Farah mithl hamamit is-sala:m (JSA)

Farah like dove the-peace

'Farah is like a peace dove'

The study indicates that $40 \%$ of the subjects showed that hamameih 'a dove' in JSA connotes a gentle woman.20\% of the subjects indicated that hamameih connotes a gentle or a peaceful person.20\% of the subjects suggested that hamameih 'a dove' connotes freedom. Additionally, $20 \%$ of the subjects posited that hamameih a person who carries 
good news. Importantly, 100\% of the subjects indicated that hamameih has positive connotations in JSA. The researcher states that the word hamameih 'a dove' has positive connotations in al-mu 'jamal-wasi:tt and al-mu'jam Al-jami'.

The word kharuf 'asheep' means inal-mu'jamal-wasi:tt and al-mu'jamal-jami ' any of various hollow-horned mammals related to the goats, but lacking a beard in the male. People make use of its flesh and wool, a timid defenseless creature one easily influenced or led.
5. hu zai ilkharuf
he like sheep
(JSA)

'He is like a sheep'

Interestingly, $60 \%$ of the subjects stated that kharuf' in JSA connotes a man who is governed by his wife. $10 \%$ of the subjects mentioned that kharuf' connotes either a man who is governed by his wife, or it connotes a person with weak personality. $30 \%$ of the subjects mentioned the two connotations. $100 \%$ of the subjects indicated that kharuf has a negative connotation in JSA. The word kharuf' is used to describe males rather than females in Jordan. The connotations of kharuf mentioned in al-mu 'jamal-wasi:tt and al-mu 'jamal-jami'agree with the connotations of kharuf' in JSA since both connote weakness. Accordingly, kharuf 'asheep' carries negative connotation in JSA and in al-mu 'jamal-wasi:tt and al-mu 'jamal-jami'.

The word battah'duck' any of various swimming birds. Al-mu 'jamal-wasi:tit and al-mu 'jamal-jami' state that a duck with a broken leg connotes powerlessness. It has been found that the two lexicons mention nothing about the connotation of battah'duck' .

6. Ahlam battah (JSA)

'Ahlam is a duck'

The study eliminates that $70 \%$ of the subjects of the study identified that battah'duck' is used in JSA to connote either a beautiful female or a chubby female, $70 \%$ of the subjects also indicated that battah has a positive connotation. $30 \%$ of the subjects, however, were of the opinion that battah connotes a fat female and though it has a negative connotation. One may notice that the battah is used in JSA to connote females rather than males.

The word kalb'the dog' is defined in al-mu'jamal-wasi:tt and al-mu 'jamal-jami` as a wild and domesticated animal of many breeds, especially kept by people as a pet or to hunt or guard things, and it is known by its loyalty as well as its companionship with humans. However, in Jordanian Arabic, kalb' the dog' has a negative connotation as many people use it as a curse. Consider the following example from JSA:

$\begin{array}{lll}\text { 7. huwwe kalb (JSA) } & \\ \text { he } & \text { dog }\end{array}$

'He is a dog'

Interestingly, 5\% of the subjects maintained that the word kalb 'the dog' connotes dirt and impurity; $10 \%$ of subjects indicated that kalb 'the dog' connotes bad manners. Forty $5 \%$ of the subjects indicated that alkalb connotes a curse. $40 \%$ of the subjects indicated that kalba dog' connotes humiliation. $100 \%$ of subjects indicated that the word kalb has a negative connotation in JSA. On the other hand, the word kalbhas a positive connotation in al-mu'jamal-wasi:tt and almu 'jamal-jami' since it connotes loyalty.

The word hisa:n 'ahorse'is defined in al-mu 'jamal-wasi:ț and al-mu jamal-jami'asa large herbivorous mammal that eats grass. It is a domesticated animal which is used as a beast of burden, a draft animal, or for riding an athlete whose performance is consistently strong and reliable. The word hisa:n 'a horse' in al-mu 'jamal-wasi:tt and al-mu 'jamaljami'connotes fastness and politeness. Hence, it has a positive connotation in al-mu 'jamal-wasi: $\underline{\text { t }}$ and al-mu'jamaljami ${ }^{6}$. The following example from JSA is a case in point:

8. Omar qawi mithl l-hisisa:n (JSA)

Omar strong like the-horse

'Omar is as strong as a horse'

Moreover, all the subjects indicated that the hisa: $n$ has positive connotations. $60 \%$ of the subjects stated that hisa: $n$ 'a horse' connotes strength. $20 \%$ of the subjects stated that hisa:n connotes strength and good health. $20 \%$ of the subjects stated that hisa: $n$ is used to connote fastness. All the subjects reported that the word hisa: $n$ has a positive connotation in JSA.

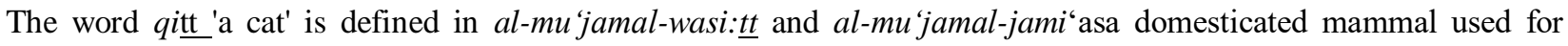

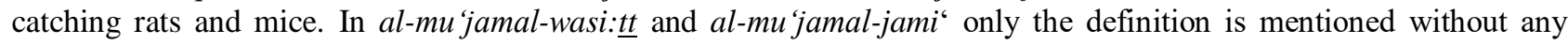
connotations. The following example from JSA is in order here:

9. hi zai ilbisah ilmghamdah (JSA) she like cat closing-eyes

'She is a closing - eyes cat'

The present study reveals that $30 \%$ of the subjects indicated that bisah 'a cat' connotes shyness. $20 \%$ of the subjects indicated that bisah connotes lack of understanding. 10\% of the subjects indicated that bisah connotes being naïve, $30 \%$ of the subjects indicated that bisah connotes lack of experience, and $10 \%$ indicated thatbisah is used to connote a poor female. $90 \%$ of the subjects indicated that bisah has a negative connotation, and $10 \%$ of the subjects indicated that bisah has a negative connotation. 
The word babaghah 'a parrot' is defined in al-mu 'jamal-wasi:tt and al-mu 'jamal-jami'as a widely distributed tropical bird that is brightly colored, has a distinctive hooked bill .It is a bird which is distinguished by mimics. The word babaghah 'a parrot' is defined in a-mu 'jamal-wasi:tt and al-mu 'jamal-jami' connotes a person who echoes another's. This goes along with the connotation of babaghah 'a parrot' in JSA. Consider the following example from JSA:

10. Ahmad babaghah (JSA)
ahmad parrot

'Ahmad is a parrot'

The researchers report that $60 \%$ of the subjects indicated that babaghah 'a parrot' connotes repeating the words of others. $20 \%$ indicated that babaghah connotes gossiping and talking too much. Intriguingly,20\% of the subjects indicated that babaghah connotes revealing secrets. The twenty subjects identified that babaghah has negative connotations in JSA.40\% of the subjects stated that babaghah has a neutral connotation. In other word, neither positive nor negative connotation.60\% indicated that babaghah 'a parrot' has a negative connotation in JSA. It seems that babaghah in al-mu 'jamal-wasi:tt and al-mu 'jamal-jami' has also a neutral connotation.

The word $m$ 'azeh 'a goat' is defined in al-mu 'jamal-wasi:tit and al-mu 'jamal-jami' as a hollow-horned strong mammal related to the sheep but of lighter build and with backwardly horns ,a short tail, and usually straight hair, and it is domesticated for its milk, wool, and flesh. The words $m$ 'azeh 'a goat' is used to describe a person or a behavior in JSA.

11. ta:sarufat-uh zai ilm'azeh (JSA)

Behavior-his like goat

'He behaves like a goat'

The study clarifies that (50\%) of the subjects indicated that $m$ 'azeh 'a goat' in JSA connotes stupidity. 10\% of the subjects suggested that $m$ 'azeh connotes immaturity, 20\% identified that $m$ 'azeh connotes mindlessness, and 20\%stated that $m$ 'azeh connotes difficulty in grasping things. $100 \%$ of the subjects indicated that stated that $m$ 'azeh has a negative connotation in JSA

\section{CONCLUSION}

At this point, it has become clear that most of the pet expressions reflect the way of thinking and the cultural background of the Jordanian society. Stated differently, pet expressions fulfill semantic and sociolinguistic functions in JSA. More importantly, in Jordan, pets may include the following animals: dogs, cats, horses, sheep, goats, donkeys, domesticated rabbits, parrots, domestic, chickens, and doves. The present study manifested that some of the connotations of pet expressions in JSA are similar to the connotations of pet expressions in al-mu 'jamal-wasi:tt and almu 'jamal-jami'such as babaghah 'a parrot' which connotes repeating the words of others. The word 'asfu:ra-h 'a bird' in al-mu'jamal-wasi:tt and al-mu'jamal-jami'connotes light things and melodious sounds, and it has also the same connotations in JSA. On the other hand, the connotations of some pet expressions used in JSA differ from those in the

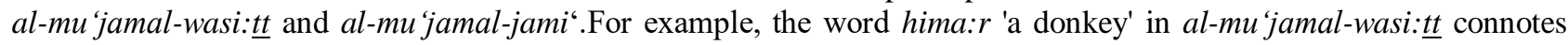
men with bad reputations or loud voices. On the other hand, it seems that hima:r 'a donkey' is used in JSA to connote stupidity.

In sum, setting light on the meaning of the pet expressions in the two lexicons as well as in the way they are used in JSA has disclosed that they have both positive and negative connotations. In some cases, JSA has the same connotation as in the two lexicons. In others, the connotation remained the same, i.e. positive or negative, but the connotation has changed. For example, hima: $r$ has negative connotation in the lexicon. JSA kept the negative connotation but changed it from 'loud voice' to 'dumb, stupid'.

\section{APPENDIX A}

Kindly fill in the accompanied Questionnaire. Answering the Questions also means giving informed consent about taking part in this study. Kindly do not write your name.

Thank you for your kind cooperation.

Questionnaire

A. What are the connotations of the bold pet expressions in Jordanian Spoken Arabic?
1. hima:r u qajid hima:r (JSA)
donkey and leading a donkey

'A donkey leading a donkey'

2. btokil zai $\begin{aligned} & \text { il-asfu:ra-h } \\ & \text { eat:3SF like the-bird-F } \\ & \text { (She) eats like a (female) bird' }\end{aligned}$
3. arnab sa'i:d fi bait-uh


rabbit happy in home-his

'Happy rabbit in his home'

4. Farah mithl hamamit is-sala:m

Fara like dove the-peace

'Farah is like a peace dove'

5. hu zai ilkharuf
he like sheep
$\quad$ 'He is like a sheep'

6. Ahlam battah
Ahlam duck
'Ahlam is

8. Omar qawi mithl l-hisa:n
Omar strong like the-horse
'Omar is as strong as a horse'
9. hi zai ilbisah ilmghamdah
she like cat closing-eyes
'She is a closing - eyes cat'

(JSA)

(JSA)

'She is a closing - eyes cat'

10. Ahmad babaghah
ahmad parrot
'Ahmad is a parrot'

11. ta:sarufat-uh zai ilm'azeh

Behavior-his like goat

'He behaves like a goat'

(JSA)

(JSA) 


\section{APPENDIX B}

Transliteration symbols for Arabic vowels and consonants

\begin{tabular}{|c|c|c|c|}
\hline Arabic alphabet & Symbol & Example & Meaning \\
\hline$\&$ & $?$ & ?amal & hope \\
\hline$\dot{H}$ & th & thaclab & fox \\
\hline ج & $\mathrm{j}$ & jamal & camel \\
\hline$\tau$ & $\underline{\mathrm{h}}$ & hub & love \\
\hline$\dot{\tau}$ & $\mathrm{kh}$ & khubz & bread \\
\hline$\dot{j}$ & $\mathrm{dh}$ & dhahab & gold \\
\hline j & $\mathrm{z}$ & zi:t & oil \\
\hline ش ش & sh & shams & sun \\
\hline ص & $\underline{\underline{S}}$ & sayf & summer \\
\hline ض & $\underline{\mathrm{d}}$ & dayf & guest \\
\hline b & $\underline{\mathrm{t}}$ & ti:n & mud \\
\hline ל & $\mathrm{TH}$ & THuhr & noon \\
\hline$\varepsilon$ & $\mathrm{c}$ & cabd & slave \\
\hline$\dot{\varepsilon}$ & gh & gharb & west \\
\hline ق & $\mathrm{q}$ & qalam & pencil \\
\hline g & $\mathrm{W}$ & ward & rose \\
\hline ي & $\mathrm{y}$ & yawm & day \\
\hline
\end{tabular}

\section{REFERENCES}

[1] Al-Attyah, M. (2012). Al-Mu'jam Al-Jami‘. Egypt: Dar Al Nawader.

[2] Allan, K.(2007).The pragmatics of connotation . Journal of Pragmatics, 39 (6):1047-1057.

[3] Al-Rawashdeh, M. (2016). The connotations of animal names used in describing people in the City of Shoback-Jordan. Unpublished M.A Thesis. Mu'tah University, Al-Karak, Jordan.

[4] Al-Zayyat, I, Hamed, A. and Al-Najar, M. (2001). Al-Mu'jamAl-Wasi:tt. Beirut: Dar Al Fikr.

[5] Al-Zoubi, I. (1999). The translability of animal names in the holy Quran. Unpublished M.A. Thesis. Yarmouk University, Irbid, Jordan.

[6] Anjomshoa, L. and Firooz, S. (2015). The comparison of connotative meaning in animal words Between English and Persian expressions and their translation. International Journal on Studies in English Language and Literature (IJSELL), 3(2): 65-77

[7] Griffith, P. (2006). An Introduction to Language Semantics and Pragmatics. Edinburgh: Edinburgh University Press.

[8] Goatly, A. (2006). Humans, animals and metaphor. Society \& Animals, 14 (1): 15 - 37.

[9] Imran, A. (2011). A cognitive semantics analysis of Malay proverbs related to the dog (Canis Familiaris). Journal of Language Studies, 11(1), 125-141. http://www.ukm.my/ppbl/Gema/GEMA\%20vol\%2011\%20\%281\%29\%202011/abstract\%20pp125_ 141.pdf.

[10] Kovecses, Z. (2010). Metaphor: A practical introduction. (2nd Edition). Oxford: Oxford University Press.

[11] Lakoff, G and Turner, M. (1989). More than cool reason. A field guide to poetic metaphor. Chicago and London: The University of Chicago Press.

[12] Peled-Shapira, H. (2009). From conventional to personal, or: What happened to metaphor under the influence of ideology The case of Ghā'ibTu' Ma Farmān. Journal of Semitic Studies, 54(1): 227-249.

[13] Philip, G. (2011). Coloring Meaning .UK: John Benjamins Publishing Company.

[14] Rodríguez, L. (2009). Of women, bitches, chickens and vixens: Animal metaphors for women in English and Spanish. Culture, Language and Representation, 7: 77-100.

[15] Salman, H and Barjes, M. (2019). This means the inappropriate use of dog proverbs in the formal type of interactions in England and Iraqi Arabic speech communities. Journal of Language Studies, v 2, n. (1): 1-16.

[16] Siefring, J. (2004). The Oxford Dictionary of Idioms. Oxford: Oxford University Press.

[17] Soskice, J. (1994). Understanding Metaphor in Literature. London: Longman Group.

Helen A. Al-Ghoweri is an Assistant professor of Linguistics at English Language and Literature Department, Faculty of Arts and Sciences at The World Islamic Sciences \& Education University (WISE) in Jordan. She has got her Ph.D from the University of Jordan in 2018, and she has taught many courses in linguistics. Her research interests include Sociolinguistics, Discourse Analysis, Syntax, Language Acquisition and Semantics.

Ayman Yasin is currently the head of the Coordination Unit for Service Courses at Princess Sumaya University for Technology in Jordan. He studied linguistics at Purdue University in Indiana, USA (2008-2012). He is interested in social sciences in general and in linguistics in particular. He has published ten papers in syntax, phonology, translation, and cinema. Dr. Yasin has also taught MA and $\mathrm{PhD}$ courses in linguistics and translation at the University of Jordan (part timer). He has experience in IELTS tests and he serves as a reviewer in several journals. 
Jibrel Al-Saudi is an Assistant professor of Linguistics at English Language Department, Faculty of Arts and Sciences at The World Islamic Sciences \& Education University (WISE) in Jordan. He is also the Director of Language Centre. His research interests include Semantics, Sociolinguistics, Discourse Analysis, Translation, Morphology, Syntax, Language Learning and Acquisition. 